\title{
Effect of Aging Heat Treatment on the Mechanical Properties of SiC Reinforced 7075 Al-Alloy Composites Manufactured by Vortex Casting Method
}

\author{
Pınar Uyan ${ }^{1, *}$, Remzi Gürler ${ }^{2}$ \\ ${ }^{1}$ Metallurgy Program, Vocational School, Bilecik Seyh Edebali University, 11210, Bilecik, Turkey \\ ${ }^{2}$ Metallurgy Institute, Eskişehir Osmangazi University, Eskisehir, Turkey
}

Copyright $@ 2018$ by authors, all rights reserved. Authors agree that this article remains permanently open access under the terms of the Creative Commons Attribution License 4.0 International License

\begin{abstract}
Nowadays, light part production by the strategies of performance improving known as 'Engine Downsizing' by decreasing the engine size is popular. $\mathrm{Al}-\mathrm{Zn}-\mathrm{Mg}$ alloyed composites reinforced by $\mathrm{SiC}$ particle are mostly produced by powder metallurgy. In fact, Liquid mixing casting technique alternatively developed against the powder metallurgy has more than advantageous when taking into the consideration of its production capacity, production cost and part production similar to the definitive form. In this study, the hardness variation of SiC particle reinforced composites manufactured by the method of affordable 'Vortex Casting' and in different amounts by weight and 7075 alloy after aging process in different times at $140^{\circ} \mathrm{C}$ and $230^{\circ} \mathrm{C}$ was reviewed and their microstructure analyses were made accordingly. After 16 hours aging of 7075 alloy and the composites reinforced by $5 \% \mathrm{SiC}$ at $140^{\circ} \mathrm{C}$ and 12 hours aging in the composites reinforced by $3 \% \mathrm{SiC}$, at $230^{\circ} \mathrm{C}$, after 9 hours aging in all materials, the maximum hardness value was measured. In higher aging temperature, due to the fact that max hardness was achieved in shorter period, in lower aging temperature, higher hardness was achieved.
\end{abstract}

Keywords Metal Matrix Composite, Precipitation Hardening, Hardness

\section{Introduction}

The requirements of producing more quality products and marketing such products with low costs oblige the development of new generation materials. Aluminum alloy is produced from the $\mathrm{SiC}$ particle reinforced composited with matrix and automative parts where the hardness and wearing properties are very important, such as segments, brake pedal, pistons, cylinders and pulleys $[1,2]$. The average weight of the parts in a vehicle is about $10 \%$ of the total weight. Decreasing in each 1000 gr weight means the lower 0,6 liters of oil consumption. On the other hand, the lower oil consumption means lower exhaust emission and working cost. Due to the fact that aluminum and alloys have the properties such as low density, high corrosion resistance, easy workability making no concessions on security, comfort and safety, it has wide area in the automotive industry [2, 3].

MMC's reinforced by $\mathrm{SiC}$ up to $40 \%$, manufactured by the casting has drawn the commercial attention thanks to its many properties. Some of these products are shown in Figure 1 [4].

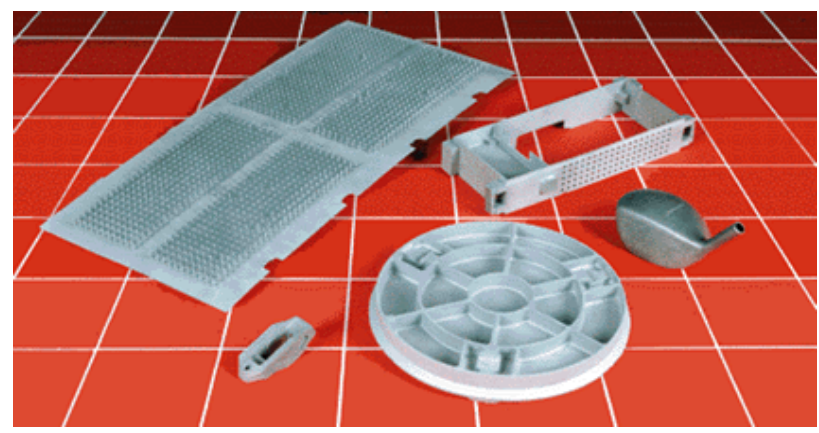

Figure 1. Some of the composite products with metal matrix [4]

Development of performance increasing strategies is important by decreasing the engine volume. Instead of forging aluminum alloys in the automotive piston groove, when using A1 matrix composites reinforced by $\mathrm{SiC}$ particle, 50\% increasing in the elastic module, 10\% decreasing in the weight have been provided [5].

Application areas of MMK materials are not limited to the engine parts, NASA and American Air Forces have carried out many studies for this purpose [6]. Due to the fact that MMK reinforced by the particle has better mechanical, isotropic and physical properties than others 
reinforced by fiber, development of their production and properties are important [2, 7].

Generally, SiC particle reinforced composites with Al-Zn-Mg alloyed matrix are manufactured by powder metallurgy and information about the composites manufactured by the techniques of solidification are limited [8].

Composites are the structures where metal and nonmetal materials are coexisting and they should reveal properties so that the components creating themselves could not have them alone. In order to obtain optimum properties in the composites, the homogenous distribution of a material should be provided in other material [1]. The composites are the materials composing two or more than two macro components in which their figures and/or chemical components are different and could not degraded within each other [9]. Modern engineering composites could be defined as "designed microstructures" by adding the dispersed phase having micron dimensions and reinforcing elements [10].

According to the shapes of the structural components, the composites could be combined into five groups such as composites reinforced by the particle, composites reinforced by the composites, plate shaped composites, laminated composites and filled composites. According to the current matrix material, composites are divided into three main groups such as polymer, ceramic and metal matrix composites [11].

The polymers are cheap and easy working materials. However, they have lower temperature of use, electrical and thermal conductivity [12]. Ceramic materials are very hard and brittle, they have low thermal shock resistance and toughness. For this reason, when they meet sudden damage in the terms of use, their using in some areas is dangerous [13]. Despite some disadvantageous, the most important reason of using the composites with metal matrix when considering the composites with ceramic matrix as high temperature material are is that the metal science and technology is beyond from the ceramics [14]. Due to the fact that MMC materials are continuously reinforced by the fiber, wicker or particles, the high strength could be achieved [15].

Many factor such as thermal expansion of matrix, machinability, hardness, thermal conductivity and electrical conductivity, procurement, area of utility are effective in the selection of the matrix material that create the composite. Graphical comparison of the temperature and density properties of different matrix materials has been already performed [16]. Matrix metal should have sufficient strength and ductility to transmit the strains on it to the reinforcing member. When the difference between the thermal expansion coefficients of matrix and reinforcing member is big, the permanent thermal stress at high temperatures could occur [17].

7xxx serial aluminum alloys have been widely used as the matrix material in the working conditions because of thermal stability at high temperatures and due to the fact that it has higher hardness and strengths than other $\mathrm{Al}$ alloys, their lower densities, high thermal and electrical conductivity and their cost efficiencies, these are preferred as the best matrix material [2].

Reinforcing member is as effective as matrix in the development of the properties of the composites. There are important factors in the selection of the ceramic reinforcing member. These are; elastic module, strength, hardness, density, melting temperature, thermal stability, thermal expansion coefficient, dimension and figure as well as harmony with the matrix and cost.

The properties to provide using the $\mathrm{SiC}$ as reinforcement are; its low density $\left(3.2 \mathrm{~g} / \mathrm{cm}^{3}\right)$, high hardness ( $\mathrm{SiC}$ is the hardest material after diamond and boron carbide) and it has perfect resistance against chemicals. SiC has high strength and it protects its strength up to $1600^{\circ} \mathrm{C}$. Its elastic module is $414 \mathrm{GPa}$. The oxidation resistance of $\mathrm{SiC}$ is good and in many places, it could be used easily up to 1500 and $1650^{\circ} \mathrm{C}$. Its thermal conductivity is high and thermal expansion coefficient is low [18].

The production methods of MMC are divided into three as liquid phase, solid phase and reaction production method based on the temperature of the matrix during the production [6]. In spite of the fact that MMK production by reaction is a function of the liquid and solid production methods, many researchers divided production methods into two groups liquid phase and solid phase production methods [16]. By means of the casting and reaction developed as the alternative to the powder metallurgy, MMC production techniques are cheap and practical [5]. Liquid mixing casting technique from liquid techniques is ahead in terms of production capacity and cost efficiency in the engineering applications [19].

Powder metallurgy, extrusion, diffusion bonding etc. as the solid phase production methods could be taken into the consideration. Additionally, as the liquid phase production methods, liquid metal infiltration, pressure casting, reaction method and liquid tempering method could be considered. Liquid phase production methods are more advantageous than solid phase production methods. Solid phase production methods require longer time. Liquid phase production methods have been mostly preferred because of their production cost and part production similar to them. On the other hand, in the liquid phase production methods, although some problems could be met such as insufficient wetting, gas pocket, particle sedimentation, segregation, deposition in grain boundary, unhomogenous mixing, such problems could be minimized by checking the process parameters [20]. However, such problems could be minimized by checking the process variables. In the vortex method, in the controlled atmosphere, within the molten matrix metal, the composites are produced by adding the reinforced materials to the vortex by the help of 
a mixer. Mixing process and additions should be made in the controlled atmosphere. If the process variables could not be checked well, the porosity ratio could be increased up to $30 \%$ [20]. The method is shown as schematic in Figure 2. The casting quality depends on the distribution of the particles. The factors that affect the particle distribution are; rate of cooling, fluidity of the liquid, specific weight of the particle and melt, the volume rate of the particles, the figure and dimension, composition of the crystalline phases, morphology and interaction with the particles, nucleation of the first phases in the ceramic, pushing or pulling the particles from solidification interface and the force coming from outside during the solidification [15]. The bonding force and porosity in the interface in the steps of this process affect the mechanical properties of the composite.

Power of mixer, speed of mixer, pre-heating temperature of the mold, particle addition speed and casting speed are important parameters in the production of successful composite [2].

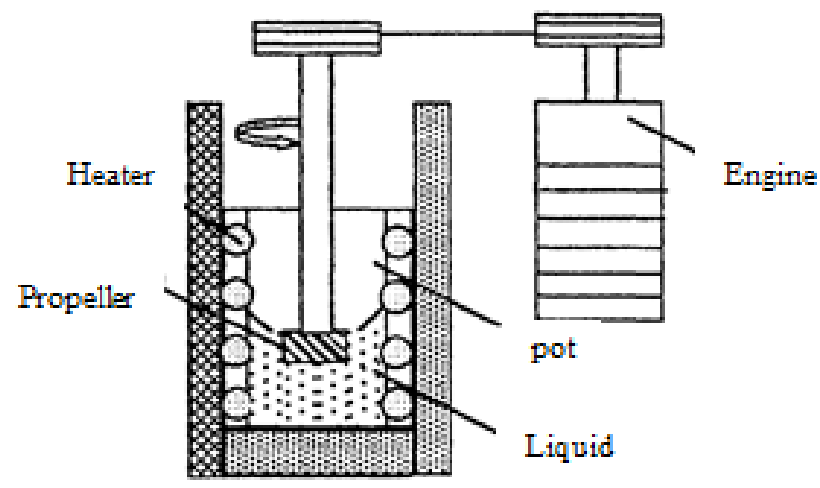

Figure 2. Schematic picture of the ceramic particle mixing method in the melted metal

Mixer speed, mixing pin and dimensions and the position of the mixing pin in the liquid are the other variables of this method. The casting method enables complicated figures and number of part production.

When reviewing the studies about the vortex method, in the composites that were produced by adding $18 \% \mathrm{SiC}$ particles in volume and in the dimension of $40 \mu \mathrm{m}$ to 5024 aluminum alloy, it is stated that the fractures occurred in the areas where the intermetallic components and the homogenous distribution was obtained and when SiC volume rate are increased, the porosity are also increased [8]. In the composites by adding $\mathrm{SiC}$ particles to 6061 aluminum alloy at the rate of $10-20 \%$ and in the dimension of $20 \mu \mathrm{m}$, it was observed that $\mathrm{SiC}$ particles have been very much accumulated in the grain boundary. It was found that two stage mixing develops the wetting in the interface of $\mathrm{Al}-\mathrm{SiC}$ [21]. In different $\mathrm{SiC}$ volume rates, the homogenous distributions of $64 \mu \mathrm{m}$ SiC particles were provided. When SiC volume rate increases, it was found that Vickers Hardness value increases [2].

Heat treatments that have been made to optimize the properties of the aluminum alloys affect the microstructure and mechanical properties of the material. Aging is the progress of the physical and mechanical properties of the material as a result of the precipitation of a phase from supersaturated solid phase by the effect of time and temperature. By means of T6 heat treatment, the highest hardness values are achieved from 7075 aluminum alloys [2, 22-24].

In A1-5\% Zn- $2 \% \mathrm{Mg}$ alloy, it was found that the highest strength achieved by the aging occurred at $20^{\circ} \mathrm{C}$ in 5 days and then 48 hours at $120^{\circ} \mathrm{C}$ by double aging is related to small but intensive GP areas [25]. In the composites of $\mathrm{Al}-\mathrm{Zn}-\mathrm{Cu}-\mathrm{Mg}$ reinforced by $\mathrm{SiC}$ particle, it was said that the particles delay the aging. Lack of interaction between $\mathrm{Zn}$ and dislocations and due to the availability of $\mathrm{MgO}$ particles in the matrix $\mathrm{Mg}_{2} \mathrm{Si}(\beta)$ and particle interfaces, it was anticipated that the consumption of the $\mathrm{Mg}$ atoms in the matrix retards the aging [26]. However, in other study, after the process of solution treated at $460{ }^{\circ} \mathrm{C}$ in 40 minutes, 12 and 40 hours aging at $140{ }^{\circ} \mathrm{C}$ was applied and due to the lack of interaction between $\mathrm{Zn}$ atoms and dislocation and the consumption of the $\mathrm{Mg}$ in the matrix, it was said that $\mathrm{SiC}$ particles in the composite of Al-Zn-Cu-Mg matrix accelerates the aging [27]. It was proven that after the aging and over aging the samples, in addition to the TEM images and coarse impurity on the grain boundaries, some more coarse impurity is available in the matrix and particle interfaces. Additionally, many researchers believe that aging process is encouraged by the reinforcements. However, the reinforcements could not change the aging order [28]. Some researchers keep dislocations in the forefront as the preferred area for the precipitation nucleation [29]. Differences between the studies show the complicated effect of the SiC particles in the aging process of the composites with Al metal matrix.

There are many microstructural changes that affect the mechanical properties. These are; aging conditions of the matrix materials, particle type, volume fraction and dimension [30].

The properties of $7075 \mathrm{Al}$ matrix composites reinforced by SiC have been reviewed before aging, during aging and after over aging and in the reinforcement that was done by thicker particles, it was determined less yield as well as tensile strength and less ductility when comparing with others made by thinner particles. Solution treated for 1 hour at $465^{\circ} \mathrm{C}$ and then quenching was made. In the condition of pre-aging, aging for 1 hour at $135^{\circ} \mathrm{C}, 12$ hour at $135^{\circ} \mathrm{C}$ in the condition of aging and 12 hour at $135^{\circ} \mathrm{C}$ in the condition of over aging was made accordingly. In the process of over aging, a second aging was made for 6 hours at $170^{\circ} \mathrm{C}$. On the other hand, in the condition of aging, when the dimension of particle is increased from $13 \mu \mathrm{m}$ to $60 \mu \mathrm{m}$, ductility has decreased however thickness has increased. This shows the importance of the gaps between the particles [30]. 
The reinforcement in A1 alloys with 7xxx serial high strength could be reason for decreasing in yield and tensile strength [31]. In the metal matrix composites reinforced by the particle, the particles could be broken during the tensile testing [32].

By applying different heat treatments to the composites with Al-Zn-Mg alloy matrix reinforced by SiC particle produced by the solidification, the hardness and strength of the matrix were increased. The hardness was amplified rapidly in first five hours in each material. Even after 96 hours aging, due to the fact that hardness values remain stable, it was said that SiC particles have not affected the aging behavior. $18 \%$ composite has the lowest hardness. Full aging period for 16 hours is valid for alloy and composites. It was seen that the properties of the composites depend on the process technique and thermomechanical process that was consecutively applied. Lower hardness values could be based on the changes in the composition of the matrix because of interfacial reaction and in the higher volume fraction (18\%) composites, lower hardness could show higher Mg loss [8].
In the vortex method, casting quality and mechanical properties depend on the distribution of the particles. For this reason mixing should be very good [15]. For homogenous mixing, in this study, a new casting furnace was designed, unlike previous work. At the same time the mixer mechanism, which can both rotating and up and down, moving has been added to furnace.

\section{Materials and Method}

\subsection{Matrix and Reinforcement Material}

As the matrix material, $7075 \mathrm{Al}$ alloy from $\mathrm{Al}-\mathrm{Zn}-\mathrm{Mg}$-Cu serial alloys having high strength values in the room temperature and showing superplastic properties was used. The chemical composition, physical properties and some mechanical properties of 7075 aluminum alloy are given in Table 1 and Table 2 respectively. Alloy was provided from Eskişehir Air Supply Maintenance Center. $\mathrm{SiC}$ particles in which density are $3.2 \mathrm{~g} / \mathrm{cm}^{3}$, grain size is approximately $44 \mu \mathrm{m}$ were used.

Table 1. Chemical composition of 7075-Al alloy (amount of the components as \% weight [33])

\begin{tabular}{|c|c|c|c|c|c|c|c|c|c|}
\hline $\mathrm{Zn}$ & $\mathrm{Mg}$ & $\mathrm{Cu}$ & $\mathrm{Cr}$ & $\mathrm{Mn}$ & $\mathrm{Si}$ & $\mathrm{Fe}$ & $\mathrm{Ti}$ & $\mathrm{Zr}+\mathrm{Ti}$ & $\mathrm{Al}$ \\
\hline $5.1-6.1$ & $2.1-2.9$ & $1.2-2$ & $0.18-0.28$ & Max 0.3 & Max 0.4 & Max 0.5 & Max 0.2 & Max 0.25 & 90 \\
\hline
\end{tabular}

Table 2. Some physical and mechanic properties of 7075-Al alloy [33]

\begin{tabular}{|c|c|c|c|c|c|c|c|c|}
\hline $\begin{array}{l}\text { Heat Treatment } \\
\text { Condition }\end{array}$ & $\begin{array}{l}\text { Melting Range } \\
{ }^{\circ} \mathrm{C} \\
\end{array}$ & $\begin{array}{c}\text { Thermal Conductivity } \\
\text { W/m.K }\end{array}$ & $\begin{array}{l}\text { Heat Capacity } \\
\text { J/g. }{ }^{\circ} \mathrm{C} \\
\end{array}$ & $\begin{array}{l}\text { Density } \\
\text { gr/cm3 }\end{array}$ & $\begin{array}{c}\text { Hardness } \\
\text { HV }\end{array}$ & $\begin{array}{c}\text { Tensile Strength } \\
\text { MPa }\end{array}$ & $\begin{array}{c}\text { Yield Strength } \\
\mathrm{MPa}\end{array}$ & $\begin{array}{c}\text { Elongation } \\
\%\end{array}$ \\
\hline 0 & \multirow{2}{*}{ 477-635 } & 173 & \multirow{2}{*}{0.96} & \multirow{2}{*}{2.81} & 68 & 228 & 103 & 17 \\
\hline T6 & & 130 & & & 175 & 572 & 503 & 11 \\
\hline
\end{tabular}




\subsection{Production of the Composites}

Composites are produced by the vortex method that is among the liquid phase processes. Production was made in a resistance heating furnace that is bottom dump and its outer side is cast iron and inner side is $\mathrm{MgO}$ lined under the protective argon gas atmosphere by the vortex method that could be increased to $1200^{\circ} \mathrm{C}$ (Figure 3). First of all, melting pot was heated at $500^{\circ} \mathrm{C}$ and matrix material was put in the pot (Figure 4 a). After melting the matrix $\left(700-750{ }^{\circ} \mathrm{C}\right)$, pre-heated $\mathrm{SiC}$ particles was added. $3 \%$ and $5 \% \mathrm{SiC}$ particles was added gradually to the alloy by the mixer and it was well mixed. The mixing process was made as $\sim 800$ revolution per minute by a propeller from the casting material and an engine that turn the propeller. In order to have homogenous mixture, SiC particles were added from a near point of turning mile by a metal spoon (8 g/minutes). On the other hand, in order to have a homogenous mixture, a mechanism was added to enable the propeller turning and move up and down. After adding all $\mathrm{SiC}$ particles in the melt, it was mixed for 10 minutes. Adding the $\mathrm{SiC}$ particles and mixing process were made under the argon gas atmosphere. As a result of all these processes, the melted metal was casted to metal molds (Figure $4 \mathrm{~b}$ ) produced from the steel by means of bottom casting technique. The bar-shaped samples at the dimension of $12 \times 150 \mathrm{~mm}$ were obtained. SiC particles and steel mold was pre-heated as 2 hours in $750^{\circ} \mathrm{C}$ in the Heraeus KS-1251 furnace. In order to prevent cooling, the tank bottom was heated by flame.

\subsection{Aging Heat Treatment}

Samples was treated to 1 hour solid solution at $460^{\circ} \mathrm{C}$ and then at $140^{\circ} \mathrm{C}$ in different times $(3,6,9,12,16,20$ and 40 hours) aging process (Heraeus KS-1251 model furnace).

\subsection{Hardness Measurement}

Hardness measurement was made by the method of micro hardness measuring and $100 \mathrm{gr}$ loading was applied by 20 seconds. For each sample, 5 measurements were made and the measurement was made distant from the particles and from the matrix of the composites.

\subsection{Microstructure Analysis}

The samples were prepared by Struers trademarked cutting, grinding and polishing machines. For microstructure analysis, Olympus PMG-3 metallography and Leco-2001 image analyzing machines were used. After aging process, it was reviewed if the microstructure changes and $\mathrm{SiC}$ particle distribution in the composites are homogenous or not.

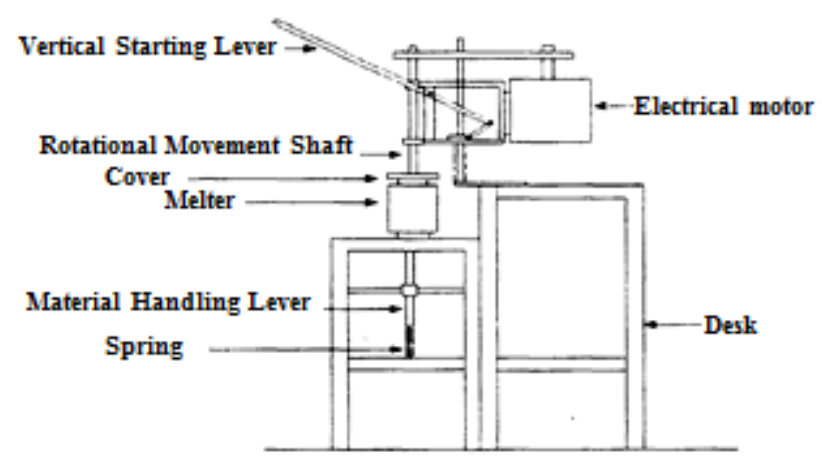

Figure 3. Schematic picture of the system used in the production [34]

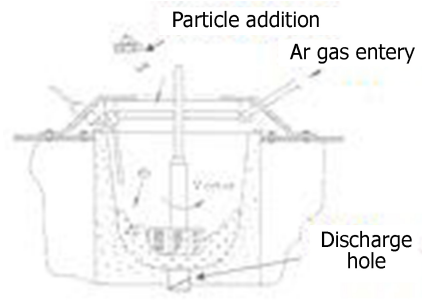

a)

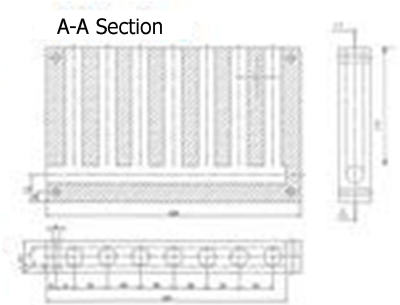

b)
Figure 4. a) Schematic picture of the melting furnace, b) Sampling mold produced by 1040 steel [35]

\section{Results and Discussion}

After casting of the composites reinforced by $3 \%$ and $5 \%$ particle with the matrix of 7075 alloy and $7075 \mathrm{Al}$ alloy, their hardness before heat treatment are respectively 135 $\mathrm{HV}, 144 \mathrm{HV}$ and 138,66 HV. The hardness values of each sample based on the aging time at $140^{\circ} \mathrm{C}$ and $230^{\circ} \mathrm{C}$ was shown in Table 3, aging time-hardness values graphics was given in Figure 5. In table 4, as a result of aging process at 140 and $230{ }^{\circ} \mathrm{C}$, changes of the hardness values measured based on the aging temperature was given. In figure 6 , depending on the aging period, aging temperature and hardness variation were shown respectively for each sample. The whole results in Figure 7 were given as graphical. Microstructure images of each sample that were aged at $140^{\circ} \mathrm{C}$ in Figure 8-10, at $230^{\circ} \mathrm{C}$ in Figure 11-13 were showed before full aging, during full aging and over aging (100X). 
Table 3. Hardness values of the samples that were aged at 140 and $230{ }^{\circ} \mathrm{C}$ in different aging period.

\begin{tabular}{|c|c|c|c|c|c|c|}
\hline \multirow{2}{*}{ Aging time (Hour) } & \multicolumn{3}{|c|}{$140^{\circ} \mathrm{C}$ Hardness (HV) } & \multicolumn{4}{c|}{$230^{\circ} \mathrm{C}$ Hardness (HV) } \\
\cline { 2 - 7 } & 7075 & $3 \% \mathrm{SiCp}$ & $5 \% \mathrm{SiCp}$ & 7075 & $3 \% \mathrm{SiCp}$ & $5 \% \mathrm{SiCp}$ \\
\hline 3 & 99 & 118,66 & 104,33 & 84,06 & 94,1 & 103,56 \\
\hline 6 & 107 & 135 & 131,5 & 116,325 & 115,33 & 124,5 \\
\hline 9 & 119 & 136 & 143 & 122 & 130 & 135 \\
\hline 12 & 189 & 185,33 & 159,33 & 105,33 & 64,53 & 69,9 \\
\hline 16 & 206 & 177 & 190,66 & 67,1 & 59,4 & 64 \\
\hline 20 & 114 & 93,66 & 100,33 & 55 & 50,288 & 54 \\
\hline 40 & 110 & 92,42 & 96,4 & 53 & 51,33 & 52 \\
\hline
\end{tabular}

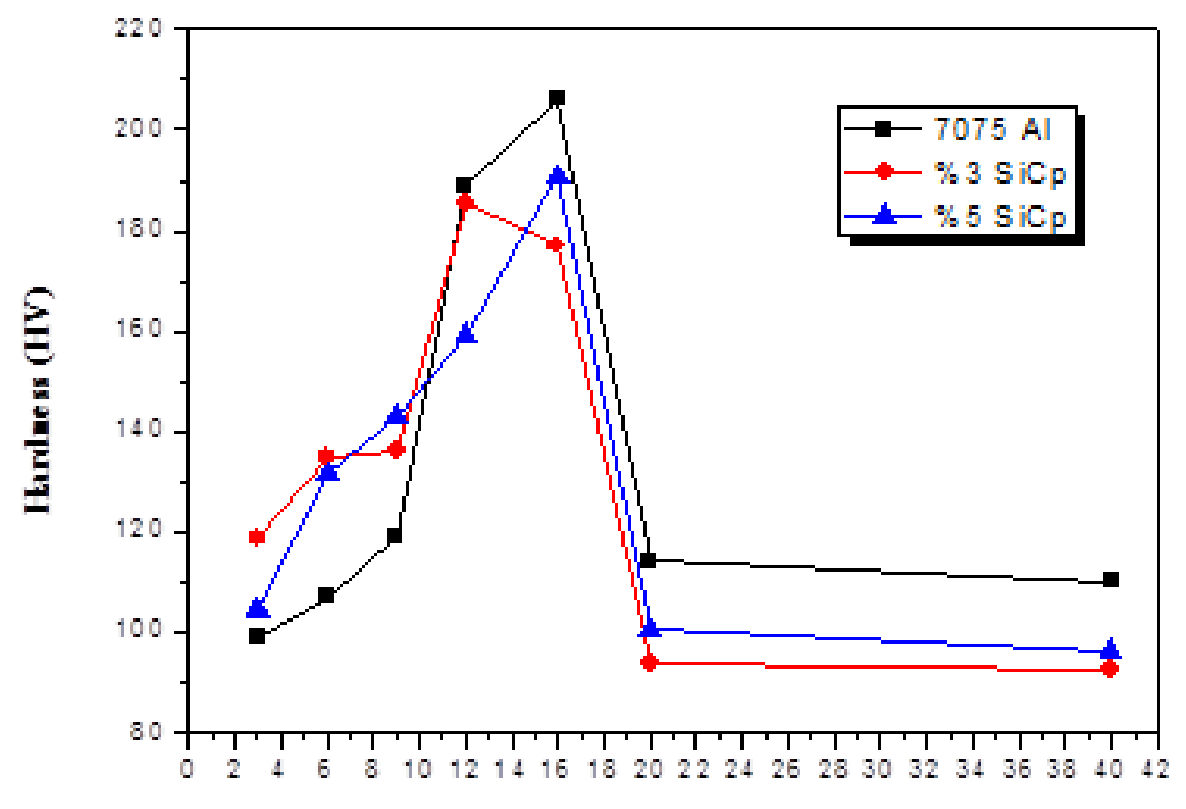

A ging time (hours)

a)

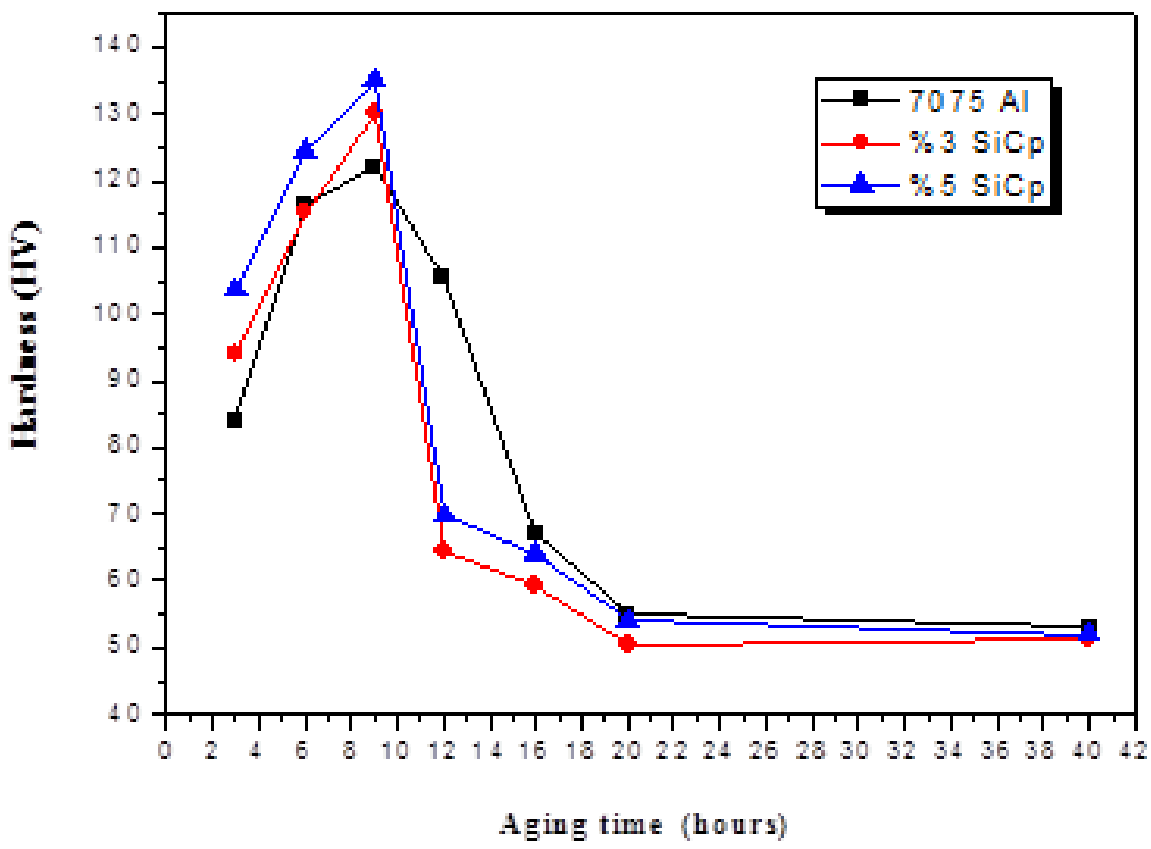

b)

Figure 5. Aging time-Hardness graphics of the composites that were aged at a) $140^{\circ} \mathrm{C}$, b) $230^{\circ} \mathrm{C}$ 
Table 4. Hardness variables of the samples based on the aging temperature

\begin{tabular}{|c|c|c|c|c|c|c|}
\hline \multirow{2}{*}{ Aging time (hours) } & \multicolumn{2}{|c|}{$7075-\mathrm{Al}$} & \multicolumn{2}{c|}{$3 \% \mathrm{SiCp}$} & \multicolumn{3}{c|}{$5 \% \mathrm{SiCp}$} \\
\cline { 2 - 8 } & $140^{\circ} \mathrm{C}$ & $230^{\circ} \mathrm{C}$ & $140^{\circ} \mathrm{C}$ & $230^{\circ} \mathrm{C}$ & $140^{\circ} \mathrm{C}$ & $230^{\circ} \mathrm{C}$ \\
\hline 3 & 99 & 84,06 & 118,66 & 94,1 & 104,33 & 103,56 \\
\hline 6 & 107 & 116,325 & 135 & 115,33 & 131,5 & 124,5 \\
\hline 9 & 119 & 122 & 136 & 130 & 143 & 135 \\
\hline 12 & 189 & 105,33 & 185,33 & 64,53 & 159,33 & 69,9 \\
\hline 16 & 206 & 67,1 & 177 & 59,4 & 190,66 & 64 \\
\hline 20 & 114 & 55 & 93,66 & 50,288 & 100,33 & 54 \\
\hline 40 & 110 & 53 & 92,42 & 51,33 & 96,4 & 52 \\
\hline
\end{tabular}

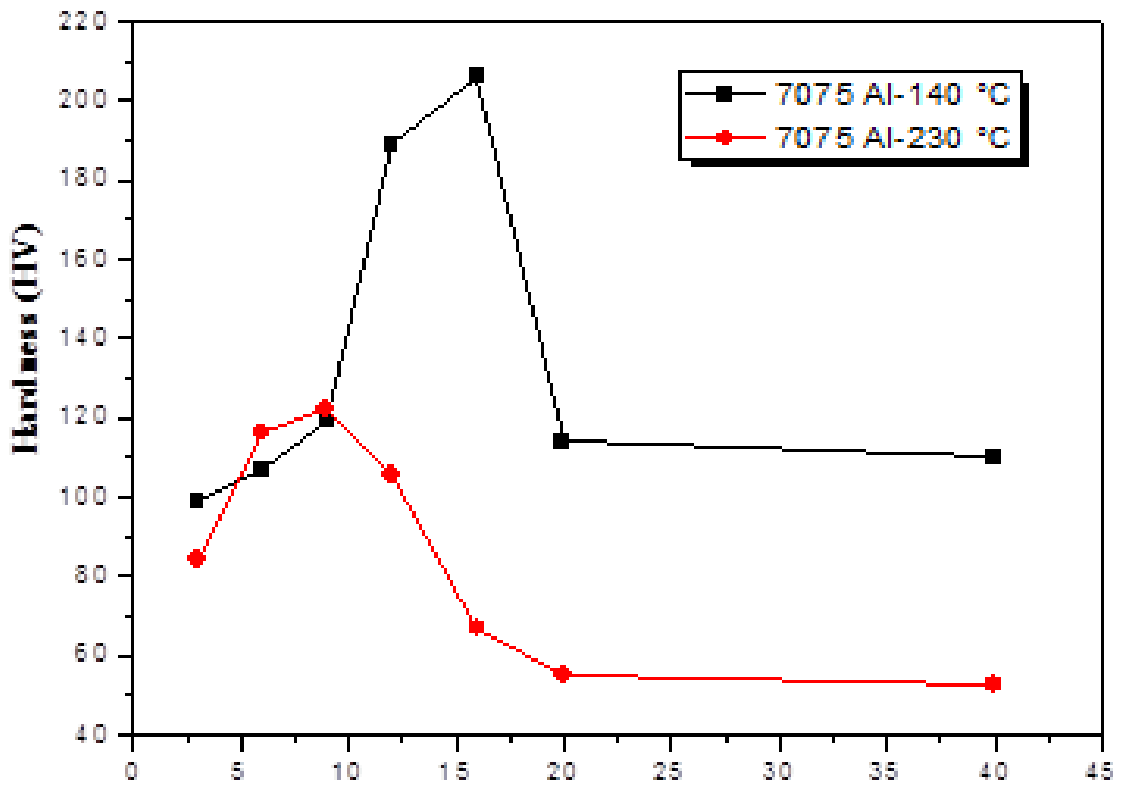

Aging time (hours)

a)

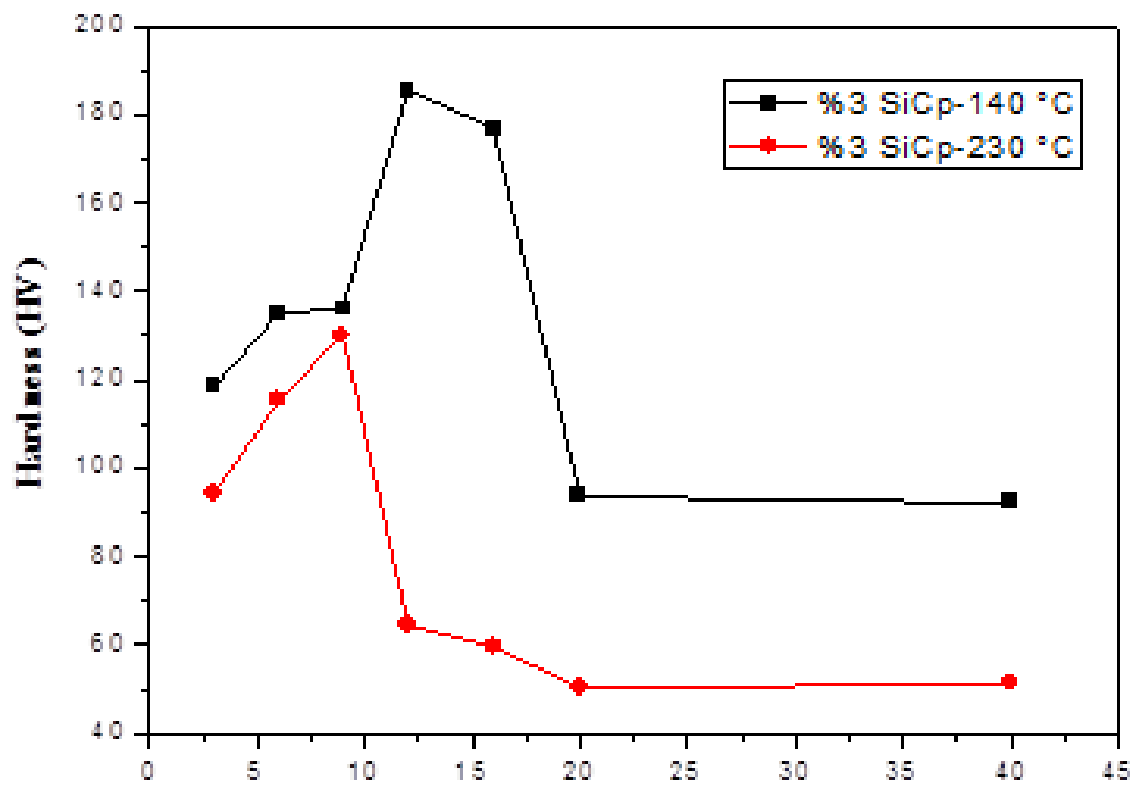

Aging time (hours) 


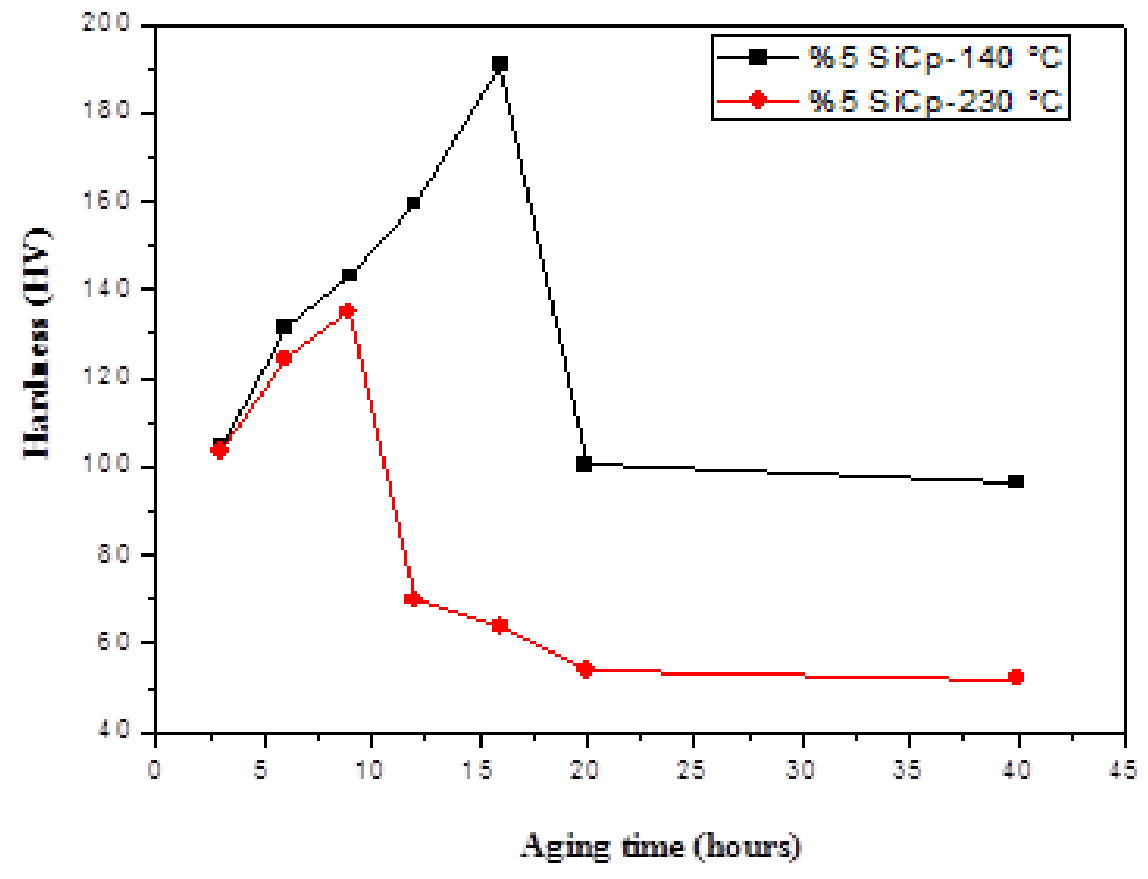

c)

Figure 6. Hardness variation based on the aging time and temperature a) 7075 alloy b) composite reinforced by $3 \%$ SiC particle c) composite reinforced by $5 \% \mathrm{SiC}$ particle

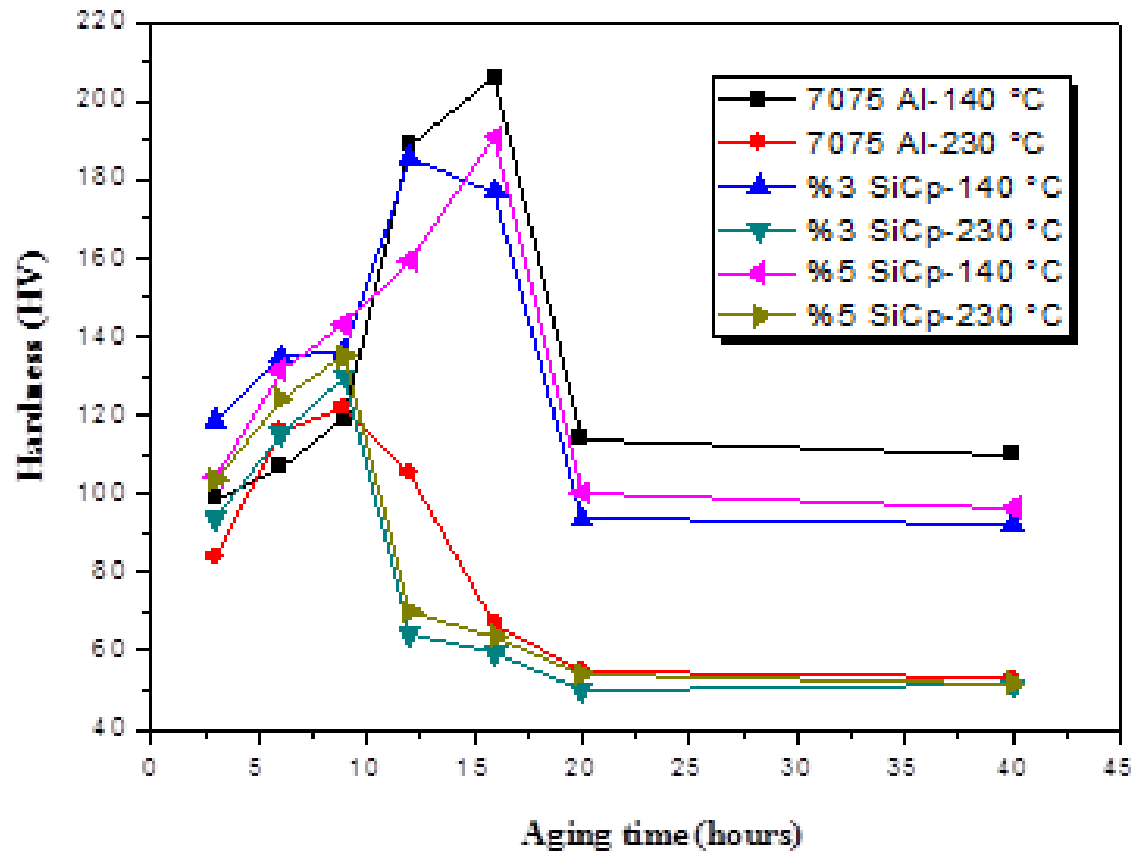

Figure 7. Hardness variation based on the aging temperature of each sample and aging time 


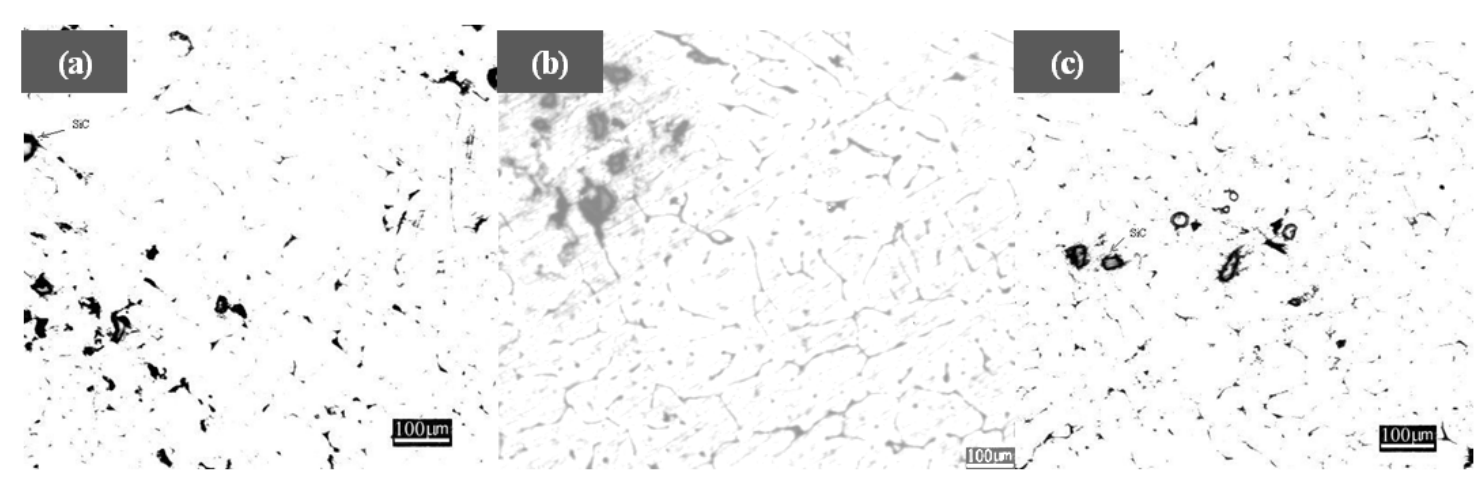

Figure 8. Microstructure images of the composite reinforced by $3 \% \mathrm{SiC}$ particle at $140^{\circ} \mathrm{C}$. a) before full aging; b) 12 hours full aging; c) after over aging for 40 hours (100x)

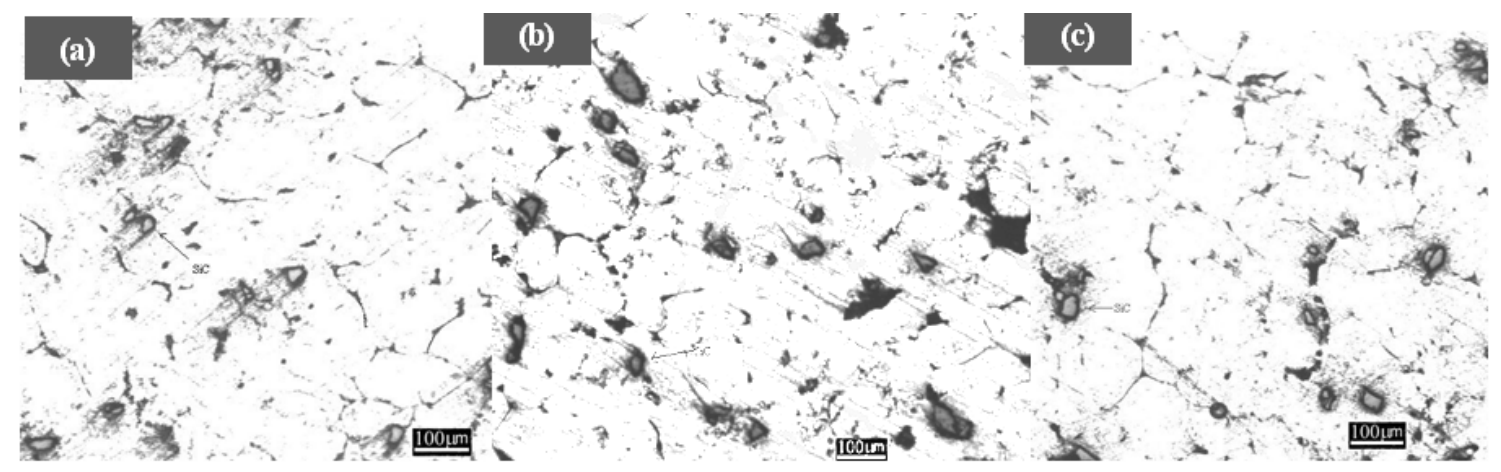

Figure 9. Microstructure images of the composite reinforced by $5 \% \mathrm{SiC}$ particle at $140^{\circ} \mathrm{C}$. a) before full aging; b) 12 hours full aging; c) after over aging for 40 hours (100x)

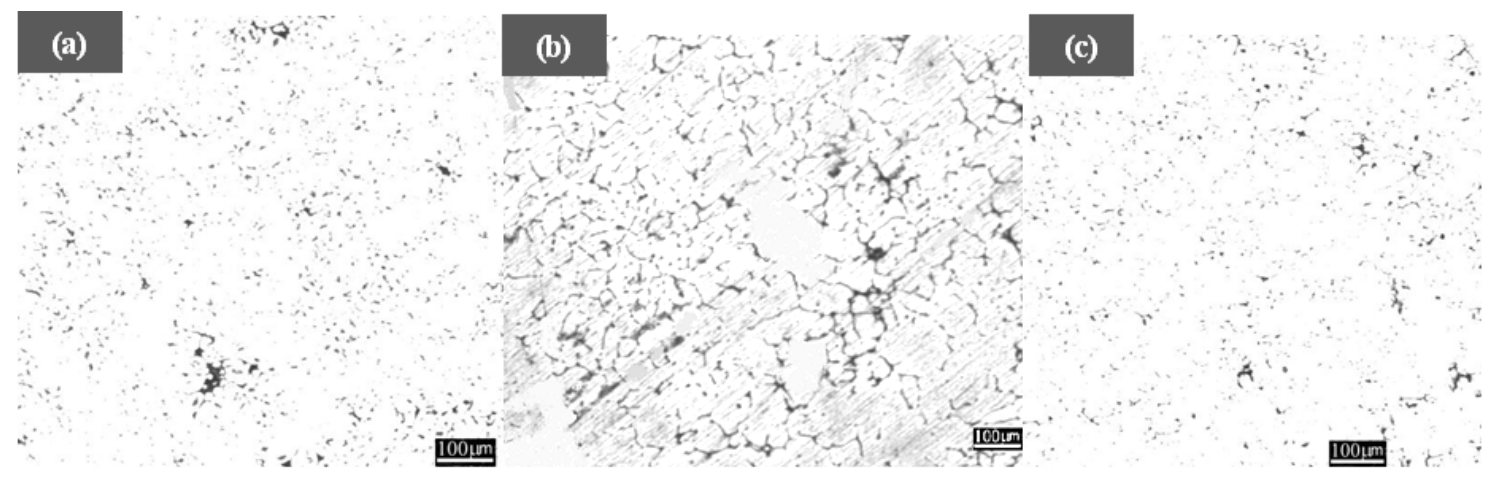

Figure 10. Microstructure images of $7075 \mathrm{Al}$ alloy at $140^{\circ} \mathrm{C}$. a) before full aging; b) 16 hours full aging; c) after over aging for 40 hours (100x)

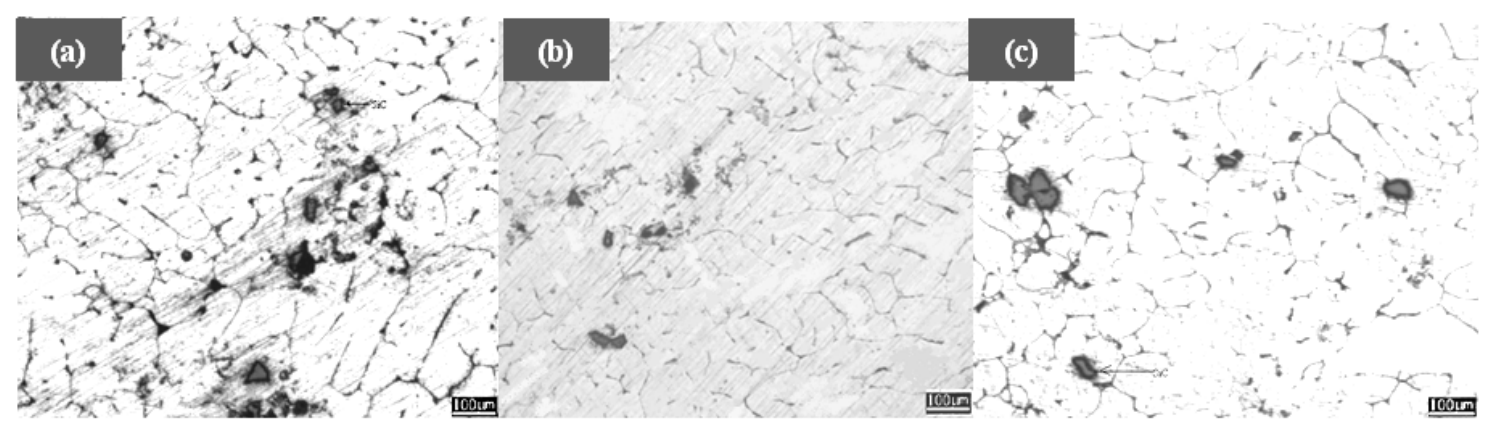

Figure 11. Microstructure images of the composite reinforced by $3 \% \mathrm{SiC}$ particle at $230^{\circ} \mathrm{C}$. a) before full aging; b) 9 hours full aging; c) after over aging for 40 hours $(100 x)$ 


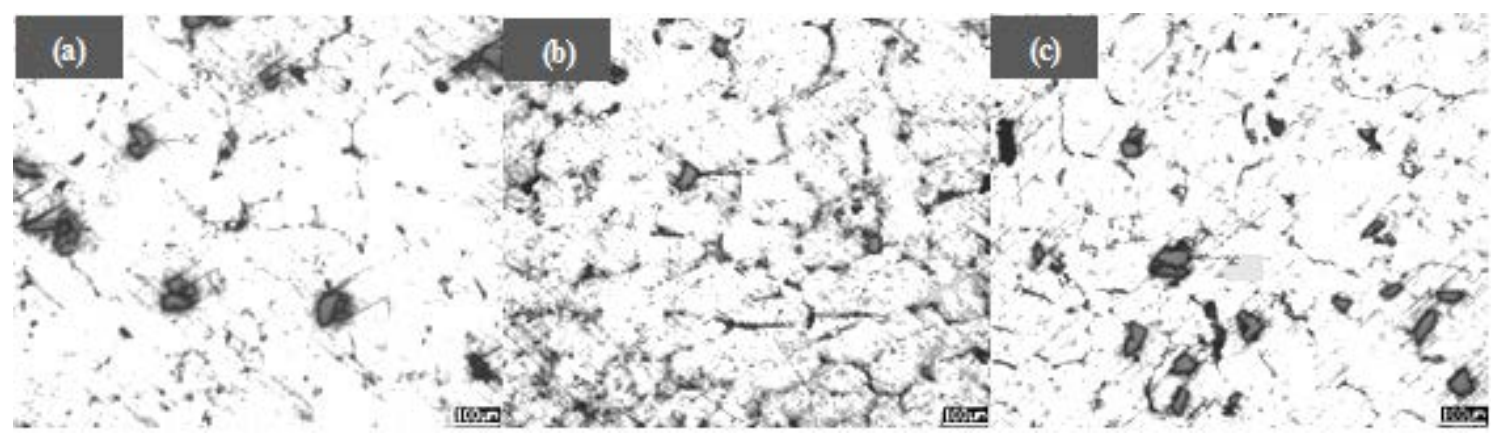

Figure 12. Microstructure images of the composite reinforced by $5 \% \mathrm{SiC}$ particle at $230^{\circ} \mathrm{C}$. a) before full aging; b) 9 hours full aging; c) after over aging for 40 hours (100x)

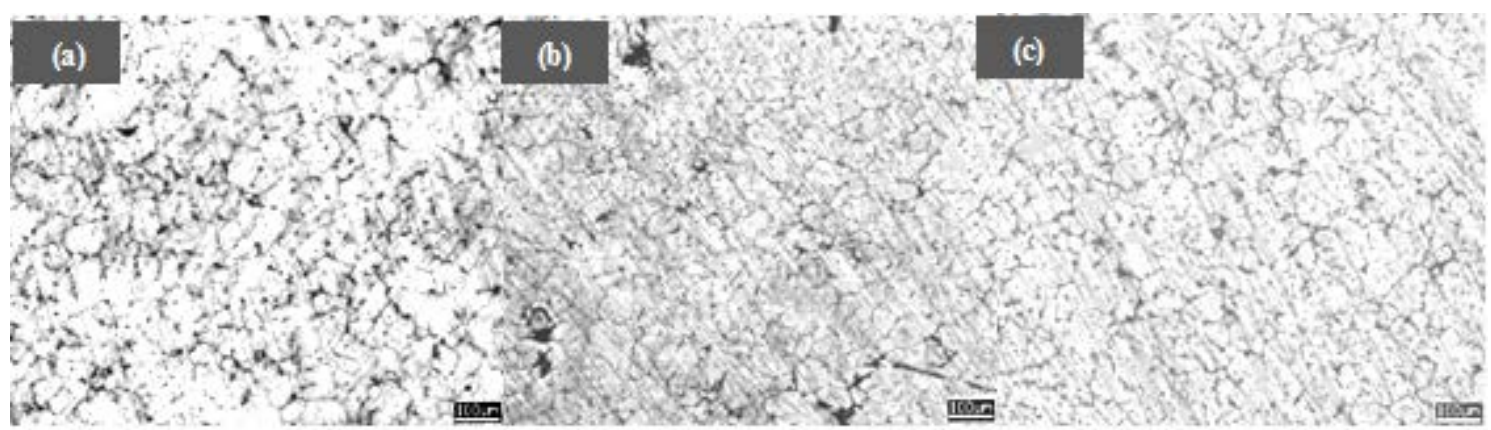

Figure 13. Microstructure images of 7075 alloy at $230^{\circ} \mathrm{C}$. a) before full aging; b) 40 hours full aging; c) after over aging for 40 hours (100x)

\section{Conclusions}

By applying aging process at $40^{\circ} \mathrm{C}$ and $230^{\circ} \mathrm{C}$ for $3,6,9$, 12, 16, 20 and 40 hours to the composites produced by Vortex method with 7075 alloy and $7075 \mathrm{Al}$ alloy matrix reinforced by $3 \%$ and $5 \% \mathrm{SiC}$ particle; their hardness variation was reviewed. As a result of aging at $140^{\circ} \mathrm{C}$, it was seen that the maximum hardness was achieved in 7075 alloy (206 HV) and reinforced by 5\% SiC composites at 16 hours (190.66 HV) and on the other hand, it was achieved at 12 hours in the composites reinforced by $3 \% \mathrm{SiC}$ (185.33 $\mathrm{HV}$ ) and lowest maximum hardness was occurred in this composite and maximum hardness was also occurred in 7075 alloy. In the conditions of full aging and over aging, for the composites reinforced by $3 \%$ and $5 \%$ particles, the hardness was lower than 7075 alloy. Before full aging, matrix hardness of the composites is more than 7075 alloy. 7075 alloy and composites that were not reinforced showed similar aging trend in accordance with the micro hardness data within the framework of experimental errors at $140^{\circ} \mathrm{C}$. Under the conditions of full aging, the particle additions accelerate the aging but under the conditions of over aging, it is the reason for decreasing the hardness.

As a result of aging at $230^{\circ} \mathrm{C}$, in each material, it was seen that maximum hardness was achieved at 9 hours. It means that $\mathrm{SiC}$ additions in the aging at $230^{\circ} \mathrm{C}$ have not affected full aging time. The maximum hardness value is 7075 alloy that is the lower one (122 HV). By the way, in the composite reinforced by $5 \%$ particle, the highest hardness value was observed (135 HV). In the composite reinforced by $3 \% \mathrm{SiC}$ particle, maximum hardness value is $130 \mathrm{HV}$. As a result of aging at $230^{\circ} \mathrm{C}$, the hardness is higher than 7075 alloy for the composites before full aging and under the full aging. By taking into the consideration of these results, it could be considered that the precipitation amount occurred under the conditions before aging could increase in the level that prevents the movement of the dislocation. The alloy and composites that are not reinforced showed similar aging trend in accordance with the micro hardness value during the aging at $230^{\circ} \mathrm{C}$. SiC addition does not affect full aging period. However, in the aging at $230^{\circ} \mathrm{C}$, the hardness drop under the over aging condition is accelerated by the addition of the particle.

It was seen that higher aging temperature $\left(230^{\circ} \mathrm{C}\right)$ is reason for max hardness value in the shortest period. However, higher hardness was achieved for each three materials under the lower aging temperature $\left(140^{\circ} \mathrm{C}\right)$ despite the longer time.

According to each experimental result;

- It is seen that $\mathrm{SiC}$ particle addition has not affected aging behavior.

- $\quad \mathrm{SiC}$ particle addition decreases hardness in over aging prominently.

- When decreasing aging temperature, full aging period and maximum hardness increases.

\section{Acknowledgements}

The author sincerely thanks to Assistant Prof. İbrahim Çelikürek and Ass. Prof. Bedri Baksan, Lecturers in 
Eskişehir Osmangazi University, Department of Metallurgy and Material Engineering.

\section{REFERANCES}

[1] S. M. Pickard, B. Derby, J. Harding, and M. Taya, Strain rate dependence of failure in $2124 \mathrm{Al} / \mathrm{SiC}$ whisker composite, Scripta Metallurgica, Vol. 22, No.5, 601-606, 1988.

[2] T. Y. Onurlubaşgil, M. Şimşir, Z. Arslan, B. Karac, M. Aydın, SiC Reinforced Al-Alloy 7075 Matrix Composites Cam Production with Vortex Method, International Participation III. Aegean Composite Materials Symposium, Kuşadası, 2015.

[3] K H. Rendigs, Aluminium Structures Used in Aerospace-Statuse and Prospects, Material Science Forum, 242: 11-24, 1997.

[4] Automotive, Online available from https://www.hitchiner.com/automotive/

[5] Y-H Seo, C-G Kang, The effect of applied pressure on particle-dispersion characteristics and mechanical properties in melt-stirring squeeze-cast SiCp/Al composites, Journal of Materials Processing Technology Vol.55, 370-379, 1995.

[6] H. Akbulut, M. Durman, F. Yılmaz, SiC Ceramic Particle Reinforced Aluminum-Silicon Metal based MMC's, 7th International Metallurgy and Materials Congress, Ankara, 1183-1194, 1993.

[7] S. Buytoz, H. Eren, Effect of Particle Reinforcements on Abrasive Wear Performance of Aluminum Metal Matrix Composites, Science and Eng. J of Frrat Univ., Vol 19, No.2, 209-216, 2007.

[8] N.V. Ravi Kumar, E.S. Dwarakadasa, Effect of matrix strength on the mechanical properties of $\mathrm{Al}-\mathrm{Zn}-\mathrm{Mg} / \mathrm{SiCp}$ composites Composites: Part A, 31, 1139-1145, 2000.

[9] V. K. Lindroos and M. J. Talvitie, Recent advances in metal matrix composites, Journal of Materials Processing Technology Vol.53, 273-284, 1995.

[10] B. Ralph, H.C. Yuen and W.B. Lee, The processing of metal matrix composites-an overview, Journal of Materials Processing Technology, Vol.63, 339-353, 1997.

[11] Mel M. Schwartz, Composite Materials Handbook, Mc Graw-Hill, 651, 1984.

[12] K.K. Chawla, A.H. Esmaeili, A.K. Datye and A.K. Vasudevan, Effect of homogeneous/heterogeneous precipitation on aging behavior of SiCp/Al 2014 composite Scripta Metall Matter Vol.25, 1315, 1991.

[13] T. Kishi, Dynamic fracture toughness in ceramics and ceramics matrix composites. Engineering Fracture Mechanics Vol. 40, No. 415, 785-790, 1991.

[14] R. L Trumper, Metal Matrix Composites-Applications and Prospects, Metal \& Materials, Vol.2, 662, 1987.

[15] P. Rohatgi, Cast metal matrix composites, ASM Handbook, Metals Park, Ohio, Vol.15, 840-854, 1992.
[16] G. Sur, Production and Machinability Analysis of Aluminum Based Composites, Graduate Thesis, Gazi University Institute of Science and Technology, 12-28, 2002.

[17] Y Şahin, Introduction to Composite Materials, Gazi publication ISBN: 9789759732400, Ankara, 48-64, 2000.

[18] T. S. Srivatsan, I. A. Ibrahim, F. A. Mohamed, E. J. Lavernia, Processing techniques for particulate-reinforced metal aluminium matrix composites, Journal of Materials Science 26, 5965-5978, 1991.

[19] M. Yılmaz and S. Santaş, Microstructure and wear properties of particle $\mathrm{SiC}$ reinforced $\mathrm{Al}$ based composites, 7th International Metallurgy and Materials Congress, Istanbul, 1175-1182, 1993.

[20] S. Ray, Porosity in Foundry Composites Prepared by the Vortex Method, Cast Reinforced Metal Composites Proceedings of the International Symposium on Advances in Cast Reinforced Metal Composites, 77-80, 1988.

[21] W. Zhou, Z. M. Xu, Casting of SiC Reinforced Metal Matrix Composites, Journal of Materials Processing Technology, 63, 358-363, 1997.

[22] M. Baydogan, H. Çimenoğlu, E.S. Kayal1, Effect of Mechanical Properties of 7075 Alloy of RRA Process, ITÜ Journal, Engineering, Vol. 3, No. 6, 108-116, 2004.

[23] R.T. Holt, M.D. Raizenne and W. Wallace, RRA Heat Treatment of Large Al 7075-T6 Components, Technical Report No: ADP010412, 1999.

[24] A. Karaaslan, I. Kaya, H. Atapek, Effect of Aging Temperature and Retrogression Treatment Time on the Microstructure and Mechanical Properties of Alloy AA 7075, Metal Science and Heat Treatment, 49, 443-447, 2007.

[25] W. F. Smith and N. J. Grant, The Effect of Multiple-Step Aging on the Strength Properties and Precipitate-Free Zone Widths in AI-Zn-Mg Alloys, Metallurgical Transactions, Vol. 1, 979, 1970.

[26] S. I. Hong and G.T. III Gray, Microstructure and Microchemistry of An A1-Zn-Mg-Cu Alloy Matrix-20 vol. \% SiC Composite, Acta Metall Mater Vol.40, No.12, 3299-3315, 1992.

[27] MA Wenchuan, GU Jialin, Z. Yong, W. Mingmei, Effect of $\mathrm{SiC}$ particles on ageing behaviour of SiCp/7075 composites, Journal of Materials Science Letters 16, 1867-1869, 1997.

[28] F.L.Matthews and R.D.Rawlings, Composite Materials: Engineering and Design, Chapman \& Hall publication, 36, 95-98, 1997.

[29] L Salvo, G L’esperance, M Suery, J. G Legoux, Interfacial reactions and age hardening in Al-Mg-Si metal matrix composites reinforced with $\mathrm{SiC}$ particles, Materials Science and Engineering, A177, 173-183, 1994.

[30] T.J.A Doel, M.H. Loretto and P. Bowen, Composites, Mechanical properties of aluminium-based particulate metal-matrix composites, Vol 24, No.3, 270-275, 1993.

[31] M. Manoharan and J. J. Lewandowski, Crack Initiation and Growth Toughness of An Aluminum Metal-Matrix Composite, Acta metall, mater. Vol, 38. No. 3, 489-496, 1990. 
[32] ] DJ. Lloyd, Aspects of Fracture in Particulate Reinforced Metal Matrix Composites, Acta Metall Mater. Vol. 39, No.59, 5-71, 1991.

[33] Aluminum 7075-O, T6, Online available from http://www.matveb.com

[34] R. Gürler, I. Mutlu, H. Çiçek, I Çelikyürek, Determination of Wear Characteristics of Silicon Carbide Particle Reinforced
Magnesium Alloy Matrix Composites, IV. International Participation Ceramic Congress, 475-480, 1998.

[35] P. Uyan, Effect on mechanical properties of the aging period of 7075 aluminum alloy matrix composites with 3\% and 5\% $\mathrm{SiC}$ particulate reinforced, M.Sc. Thesis, Eskişehir Osmangazi University Institute of Science and Technology, Department of Metallurgical Engineering, Eskişehir, 2004. 